\title{
PITFALLS IN NEONATAL CARDIAC SURGERY USING ANTEGRADE CEREBRAL PERFUSION
}

Nicole J. C. W. van Haaren, MSc, Ger B. W. E. Bennink, MD, and Jaap W. de Vries, MD, Utrecht, The Netherlands

In the past decade, advances in the surgical management of children with severe congenital heart disease (CHD) have led to a dramatic improvement in survival. The greatest impact of these advances has been on neonates with complex, and what previously would have been lethal, heart disease. However, there are

From the Department of Anesthesia and Intensive Care, UMCU, Utrecht, The Netherlands.

Received for publication April 28, 2000; accepted for publication June 16, 2000.

Address for reprints: J. W. de Vries, MD, UMCU, Department of Anesthesia and Intensive Care, KG 02.307.0/PO Box 85090, 3508 AB Utrecht, The Netherlands

(E-mail: j.w.devries@ anest.azu.nl).

J Thorac Cardiovasc Surg 2001;121:184-6

Copyright (C) 2001 by The American Association for Thoracic Surgery

$0022-5223 / 2001 \$ 35.00+0 \quad \mathbf{1 2 / 5 4 / 1 0 9 5 4 6}$

doi: $10.1067 / \mathrm{mtc} .2001 .109546$ an increasing number of reports on adverse neurologic outcomes in neonates and infants after this kind of operation, ranging from mild neuropsychologic deficits, detectable only by means of sensitive tests, to gross damage, resulting in persisting vegetative state or death. ${ }^{1-3}$ The awareness that improved survival comes at the cost of substantial neurologic morbidity has been an incentive for extensive research in this field. Some lifesaving surgical procedures are impossible without deep hypothermic circulatory arrest (DHCA), but this procedure has been linked with neurologic sequelae. Although the duration of "safe DHCA" remains unknown, adverse outcomes are more frequently observed in children with a DHCA duration exceeding 45 minutes. ${ }^{4}$ Various strategies for preventing neurologic problems and allowing the surgeon more time for optimal repair and hemostasis have been developed. One of the most promising is low-flow antegrade cerebral perfusion (ACP). ${ }^{5}$ This technique has been successfully applied in adults and is being introduced in neonatal aortic surgery. In neonatal surgery, the very small size may 

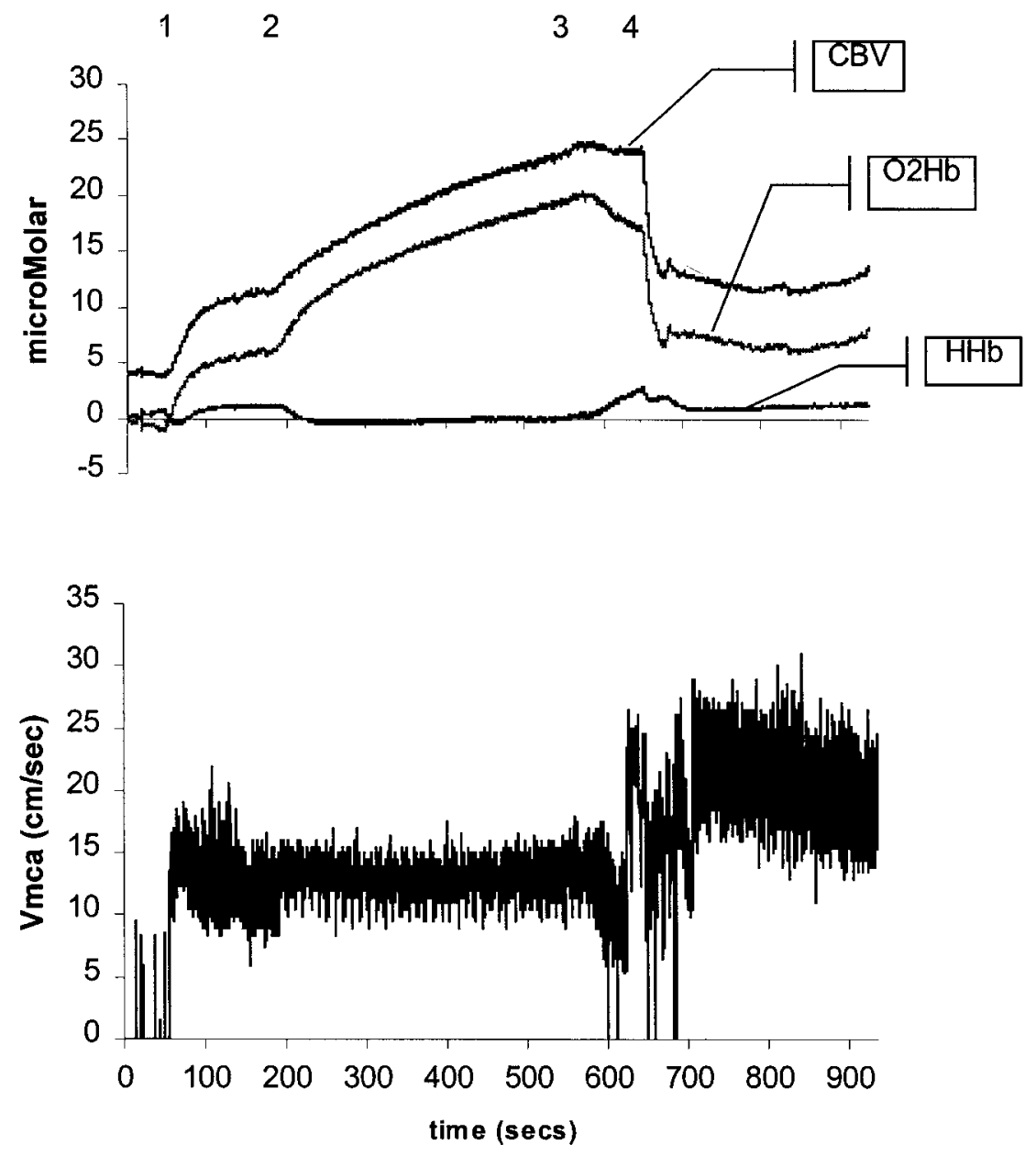

Fig 1. Top, $\mathrm{O}_{2} \mathrm{Hb}, \mathrm{HHb}$, and $\mathrm{CBV}$; bottom, $\mathrm{V}_{\text {maa }}$. Marker 1 , Initiation of $\mathrm{ACP}$ at a flow of $10 \mathrm{~mL} \cdot \mathrm{kg}^{-1} \cdot \mathrm{min}^{-1}$; marker 2, increasing flow to $15 \mathrm{~mL} \cdot \mathrm{kg}^{-1} \cdot \mathrm{min}^{-1}$; marker 3 , ACP stop; marker 4 , release of SVC snare and repositioning of the cannula and resumption of ACP at $15 \mathrm{~mL} \cdot \mathrm{kg}^{-1} \cdot \mathrm{min}^{-1}$.

cause technical problems-for example, with insertion of cannulas. We present 2 cases in which potentially dangerous problems with cannulas were detected and were corrected, guided by the monitoring of cerebral blood flow velocity and oxygenation.

\section{Clinical summaries}

PATIENT 1. A male neonate (body weight, $3.2 \mathrm{~kg}$ ) with a hypoplastic aortic arch was scheduled for aortic arch repair. General anesthesia was induced and maintained as usual. Routine monitoring was supplemented with transcranial Doppler measurement of the blood flow velocity in the left middle cerebral artery $\left(\mathrm{V}_{\text {mca }}\right.$ ) (MultiDop T; DWL, Göttingen, Germany) and near infrared spectroscopy (Oxypulse; IDKUN, Nijmegen, The Netherlands). This device is capable of measuring changes in oxyhemoglobin $\left(\mathrm{O}_{2} \mathrm{Hb}\right)$ and deoxyhemoglobin $\left(\mathrm{deO}_{2} \mathrm{Hb}\right)$ in the underlying tissue. Transmitter and receiver fiberoptic leads were placed over the left frontoparietal region.
After heparinization, arterial, inferior and superior vena cava (SVC) cannulas were inserted. During cooling, cardiopulmonary bypass flow was maintained between 2.0 and $2.5 \mathrm{~L} \cdot \mathrm{min}^{-1} \cdot \mathrm{m}^{-2}$ to achieve a rectal temperature of $17^{\circ} \mathrm{C}$. Blood gas management was by $\mathrm{pH}$-stat. Once this temperature was reached, the pump was stopped. On cessation of flow, we noted absence of $\mathrm{V}_{\text {mca }}$, a drop in cerebral $\mathrm{O}_{2} \mathrm{Hb}$ and a rise in $\mathrm{deO}_{2} \mathrm{Hb}$. A $6 \mathrm{~F}$ cannula was inserted into the right innominate artery, negotiated into the carotid artery, and snared down; the contralateral carotid artery was clamped. $\mathrm{ACP}$ was initiated at a flow of $10 \mathrm{~mL} \cdot \mathrm{kg}^{-1} \cdot \mathrm{min}^{-1}$. The mean $\mathrm{V}_{\text {mca }}$ increased to $12 \mathrm{~cm} / \mathrm{sec}$, and the $\mathrm{O}_{2} \mathrm{Hb}$ increased by \pm 7 $\mu$ mol. The ACP flow was slowly increased to $15 \mathrm{~mL} \cdot \mathrm{kg}^{-1}$. $\mathrm{min}^{-1}$. We then noted a steady increase in $\mathrm{O}_{2} \mathrm{Hb}$ and a slight decrease in $\mathrm{deO}_{2} \mathrm{Hb}$, while the $\mathrm{V}_{\text {mca }}$ remained unchanged. In addition, the fontanel started to protrude and the perfusionist noted a decrease in venous return. Flow was subsequently decreased without significant effects. Because obstructed 
venous drainage was obvious, the snare of the SVC cannula was released and the cannula was withdrawn approximately $3 \mathrm{~mm}$. This caused an immediate normalization of the fontanel pressure and a drop in $\mathrm{O}_{2} \mathrm{Hb}$. ACP was resumed with flow ranging between 12 and $15 \mathrm{~mL} / \mathrm{kg}$. The remainder of the procedure was uneventful. After the completion of the operation, the patient was transferred to the pediatric intensive care unit and his lungs were electively ventilated overnight. We were able to extubate his lungs the next morning, and the patient made an uneventful recovery. Postoperative neurologic examination, including brain sonography, revealed no abnormalities.

PATIENT 2. A male neonate (body weight, $4.2 \mathrm{~kg}$ ) with hypoplastic left heart syndrome was scheduled for a firststage Norwood procedure. Anesthesia and monitoring were identical to that of the first case. ACP was initiated at a flow of $10 \mathrm{~mL} \cdot \mathrm{kg}^{-1} \cdot \mathrm{min}^{-1}$. This did not result in an increase in $\mathrm{V}_{\text {mca }}$; also, the decrease in $\mathrm{O}_{2} \mathrm{Hb}$ and the increase in $\mathrm{HHb}$ were not affected. We did, however, note an increase in the right radial artery pressure. Flow was stepwise increased. Finally, at a flow of $50 \mathrm{~mL} \cdot \mathrm{kg}^{-1}$. $\mathrm{min}^{-1}$ the $\mathrm{V}_{\text {mca }}$ and $\mathrm{O}_{2} \mathrm{Hb}$ increased and the $\mathrm{HHb}$ decreased. On palpation, the ACP-cannula proved to be in the innominate artery. Because cerebral perfusion was adequate at this time, no attempts were made to reposition the cannula. The operation and the patient's recovery were uneventful. Postoperative neurologic examination, including brain sonography, revealed no abnormalities.

Discussion. Deep hypothermia is the commonest method of cerebral "protection" during surgery involving the aortic arch. As neurological sequelae increase in frequency and severity with increasing duration of DHCA, the time for repair is limited. ACP drastically limits the DHCA time, thus reducing the risk of brain damage, and so gives the surgeon the opportunity to perform the repair without rushing. In our hospital, ACP is applied when DHCA would outlast the time for insertion and removal of the ACP-cannula. In these cases, we routinely apply transcranial Doppler and near infrared spectroscopy monitoring of cerebral perfusion and oxygenation parameters.
In the first case above, an abnormal increase in cerebral blood volume was the first sign of venous obstruction. Alarmed by this finding, we looked for other signs and noted bulging of the fontanel and loss of venous drainage. Immediately, measures were taken; the effects of improving venous drainage are obvious.

In the second case, the ACP-cannula had slipped back into the brachiocephalic trunk. Transcranial Doppler and near infrared spectroscopy showed no relevant perfusion of the brain and, subsequently, no improvement in cerebral oxygenation at standard flow rates. This would have been undetected during surgery if these monitoring techniques had not been used, with possible deleterious consequences, as the brain would have been deprived of oxygen supply for a considerable time.

These cases show that while ACP in neonatal aortic arch surgery is an attractive alternative to DHCA, even in experienced hands it is a technique that requires constant vigilance. In our view, adequate cerebral monitoring is mandatory for the safe realization of this technique.

\section{REFERENCES}

1. Miller G, Eggli KD, Contant C, Baylen BG, Myers JL. Postoperative neurologic complications after open heart surgery on young infants. Arch Pediatr Adolesc Med 1995;149:764-8.

2. Hövels-Gurich HH, Seghaye MC, Dabritz S, Messmer BJ, von Bernuth G. Cognitive and motor development in preschool and school-aged children after neonatal arterial switch operation. J Thorac Cardiovasc Surg 1997;114:578-85.

3. Du Plessis AJ. Neurologic complications of cardiac disease in the newborn. Clin Perinatol 1997;24:807-26.

4. Newburger JW, Jonas RA, Wernovsky G, Wypij D, Hickey PR, Kuban KC, et al. A comparison of the perioperative neurologic effects of hypothermic circulatory arrest versus low-flow cardiopulmonary bypass in infant heart surgery. $N$ Engl J Med 1993;329:1057-64.

5. Pigula FA, Nemoto EM, Griffith BP, Siewers RD. Regional lowflow perfusion provides cerebral circulatory support during neonatal aortic arch repair. J Thorac Cardiovasc Surg 2000;119:331-9. 